\title{
EDITORIAL
}

\section{Kashmiri Wazwan: Are We Listening to Our Endothelium?}

In animal models of diet-induced obesity, hypercaloric (4.6 $\mathrm{Kcal} / \mathrm{g}$ ) diets have been shown to have metabolic and hormonal effects, including hyperglycemia, insulin resistance and changes in leptin profiles, ${ }^{1}$ as well as undesirable effects on blood pressure homeostasis and even cardiac remodeling. Such effects have been directly and inversely correlated with saturated and unsaturated lipid consumption, respectively. In these experimental models, it also has been elegantly demonstrated that a variety of alterations in cardiac structure and function occur due to reduced myofilament $\mathrm{Ca}^{2+}$ sensitivity, alterations in $\mathrm{Ca}^{2+}$ handling proteins and beta-adrenergic receptors. ${ }^{2-5}$ Moreover, in such models, cardiac dysfunction was due to changes in intracellular $\mathrm{Ca}^{2+}$ handling caused by reduced cardiac sarcoplasmic reticulum $\mathrm{Ca}^{2+}$ ATPase (SERCA2) activation via $\mathrm{Ca}^{2+}$ calmodulin kinase. ${ }^{6}$

Although we know that humans respond to a state of positive energy balance primarily by storing excess energy as triglycerides in white adipose tissue, ${ }^{7}$ sparse data is available on cardiovascular function and hypercaloric diets in healthy humans. Contemporary data provides little or no informa- tion on cardiomyocyte function and effects of acute caloric load on the human heart. However, the acute effects of fast food on vascular function have been reported. ${ }^{8,9}$ Such effects have been found, particularly in the postprandial state, where impaired vascular function, low grade inflammation and increased cardiovascular risk have been demonstrated. ${ }^{10-12}$ Postprandial effects on vascular function and inflammation are reversible and temporal with high-fat atherogenic meals providing a direct source of vascular stress. ${ }^{13-17}$ Recently, postprandial effects of a highfat/high-energy (HF/HE) meal on vascular function and plasma markers of endothelial function and inflammation in young healthy subjects were reported. ${ }^{18}$ The authors compared the $\mathrm{HF} / \mathrm{HE}$ meal to an average breakfast milkshake. The HF/HE shake consump- tion was associated with a more pronounced increase in heart rate, systolic blood pressure, plasma interleukine-8 (IL-8) and peripheral blood mononuclear cell gene expression of IL-8 and CD54 (intercellular adhesion molecule: ICAM-1) compared with an average breakfast shake consumption.
IL-8 might play an important role in dealing with high-fat challenges and could be an early marker for endothelial stress, a stage preceding endothelial dysfunction.

In the article "Wazwan the Kashmiri Cuisine ACaloric Bomb," Ahmad et al, report for the first time on the highcaloric density of the ceremonial Kashmiri feast "Wazwan," a primarily meat-based cuisine served usually at weddings in the Valley of Kashmir. ${ }^{19}$ The authors selected a random wedding and studied 11 Wazwan dishes. Contemporary Kashmiri weddings purportedly serve more than 30 dishes "the bigger the better" which are commonly mixed with an unending entourage of chutneys and carbonated sugar-based beverages. More often than not, the Wazwan served in honour of the bridegroom (the "Mahraaz Saal") is accompanied by a series of baked delicacies and dried fruit (or nuts) prior to the initiation of the "meat feast." Based on their study, the authors concluded by aptly calling the Wazwan "a caloric bomb."

Ahmad and colleagues estimate the caloric content of each Wazwan trami (which serves four people) to approxi- mate 22,000 calories, with each guest typically consuming approximately 5,500 calories. The calculation of the caloric content in this study is based on reference values provided by the National Institute of Nutrition, Hyderabad. According to the study authors, the cooks (wazas) were asked to keep a record of "every" ingredient used. Obviously, this is not an accurate method but an indirect calorie estimation tech- nique. In such a calculation system, calories are not determined directly by burning the foods. Instead, the total caloric value is calculated by adding up the calories provided by the energy-containing nutrients: protein, carbohydrate, fat and alcohol. Because carbohydrates contain some fiber that is not digested and utilized by the body, the fiber component is usually subtracted from the carbohydrate total before calculating the calories. Unfortunately, the authors have not provided us any details as to the method utilized.

This study does make clear that Wazwan puts a tremendous burden on the vascular system even if only taken from a caloric standpoint. However, one must not ignore the endothelial effects of the lavish oil and "ghee" used in 
preparing the majority of the dishes. It has been shown that triglyceride-rich particles may increase inflammation, and HF/HE intake can increase circulating endotoxins. ${ }^{20}$ These postprandial endotoxins are transported through the gut wall during chylomicron uptake and are able to activate inflammation, ${ }^{21}$ with circulating endotoxin levels showing more dramatic postprandial changes in people with a higher metabolic risk. During a Wazwan meal, high intake of energy, fat, saturated fat, sodium, carbohydrate and carbonated soft drinks along with low intake of antioxidants will increase vascular stress, increase platelet adhesion and cause a hypercoagulable state.

In response to physical and chemical stimuli, the endothelium regulates vascular physiology through control of vasoreactivity, inflammation, vessel growth and remodeling, monocyte adhesion, platelet activation, thrombosis and thrombolysis. ${ }^{22}$ In a state of high oxidative stress following a heavy caloric load (or HF/HE meal like the Wazwan), it is plausible that transient endothelial dysfunction leads to enhanced endothelial vasoreactivity, creating a spectrum of abnormalities that can encompass acute coronary syndrome (Figure 1). In fact, Rudolph and colleagues ${ }^{8}$ previously showed that eating a meal at McDonald's, even a "healthy" one, results in the same degree of endothelial dysfunction as 30 minutes of exposure to secondhand smoke (McAttack or Death Burger effect). Using reduction in brachial artery flow as a surrogate, the authors $^{8}$ showed that after the highest-fat meal, there was a
$22.7 \%$ reduction in brachial artery flow, which is identical to the reduction in coronary flow velocity reserve following 30 minutes of secondhand smoke exposure. It also was shown by investigators in a case-crossover study that ingestion of heavy meals can trigger acute coronary syndrome. $^{23}$ We believe that the endovascular effects (Figure 1) of Wazwan (which may culminate in an acute coronary syndrome) have neither been questioned nor illustrated in any study, including the present one.

Nevertheless, Ahmad and colleagues have made the first attempt to scratch the collective apathy of the medical community toward Wazwan. The meat indulgence of the people of Kashmir during the wedding season and complete societal fatigue toward making a healthy change strikes a sorry note. Previous attempts at regulating Wazwan via government legislation have failed, as have "social fatwas." In our opinion, nutritional education campaigns would be of paramount importance in educating the public against the harmful effects of too much Wazwan. Modern digital tools and social media could play an equally meaningful role.

\author{
M. Fuad Jan, MD ${ }^{1}$, Suhail Allaqaband, M.D ${ }^{2}$ \\ 1Wheaton Franciscan Healthcare, St. Francis Hospital, \\ Milwaukee, Wisconsin, USA,
}

2Aurora Cardiovascular Services, Aurora Sinai / Aurora St. Luke's Medical Centers, University of Wisconsin School of Medicine and Public Health, Milwaukee, Wisconsin, USA

\section{High-Energy / High-Fat Meal}

(WAZWAN)

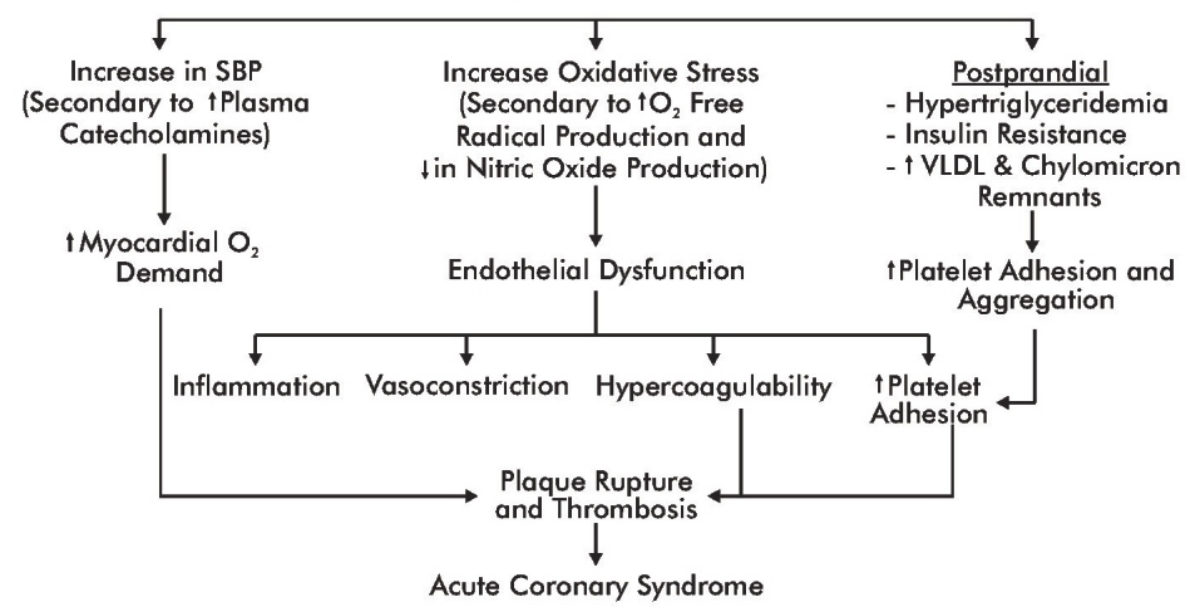

FIGURE 1. Schematic representation of the endovascular consequences of a Wazwan meal. A high-energy/high-fat meal like the Wozwan is atherogenic through both direct (endothelium-dependent) and indirect pathways. SBP = systolic blood pressure; $\mathrm{O}_{2}=$ oxygen; VLDL = very-low-density lipoprotein 


\section{REFERENCES}

1. Junior SA, Padovani CR, Rodrigues SA, et al. Extensive impact of saturated fatty acids on metabolic and cardiovascu- lar profile in rats with diet-induced obesity: a canonical analysis. Cardiovasc Diabetol 2013;12(1):65.

2. Relling DP, Esberg LB, Fang CX, et al. High-fat-dietinduced juvenile obesity leads to cardiomyocyte dysfunction and upregulation of Foxo3a transcription factor independent of lipotoxicity and apoptosis. J Hypertens 2006;24(3):549-61.

3. Ren J, Walsh MF, Jefferson L, et al. Basal and ethanolinduced cardiac contractile response in lean and obese Zucker rat hearts. J Biomed Sci 2000;7(5):390-400.

4. Young ME, Guthrie PH, Razeghi P, et al. Impaired longchain fatty acid oxidation and contractile dysfunction in the obese Zucker rat heart. Diabetes 2002;51(8):258795.

5. Strassheim D, Houslay MD, Milligan G. Regulation of cardiac adenylate cyclase activity in rodent models of obesity. Biochem J 1992;283(Pt 1):203-8.

6. Lima-Leopoldo AP, Leopoldo AS, Sugizaki MM, et al. Myocardial dysfunction and abnormalities in intracellular calcium handling in obese rats. Arq Bras Cardiol 2011;97(3):232-40.

7. Savage DB, Murgatroyd PR, Chatterjee VK, O'Rahilly S. Energy expenditure and adaptive responses to an acute hypercaloric fat load in humans with lipodystrophy. J Clin Endocrinol Metab 2005;90(3):1446-52.

8. Rudolph TK, Ruempler K, Schwedhelm E, et al. Acute effects of various fast-food meals on vascular function and cardiovas- cular disease risk markers: the Hamburg Burger Trial. Am J Clin Nutr 2007;86(2):334-40.

9. Vogel RA, Corretti MC, Plotnick GD. Effect of a single high- fat meal on endothelial function in healthy subjects. Am J Cardiol 1997;79(3):350-4.

10. Bell DS, O'Keefe JH, J ellinger P. Postprandial dysmetabolism: the missing link between diabetes and cardiovascular events? Endocr Pract 2008;14(1):11224.

11. Burdge GC, Calder PC. Plasma cytokine response during the postprandial period: a potential causal process in vascular disease? Br J Nutr 2005;93(1):3-9.
12. O'Keefe JH, Bell DS. Postprandial hyperglycemia/ hyperlipidemia (postprandial dysmetabolism) is a cardiovas- cular risk factor. Am J Cardiol 2007;100(5):899-904.

13. Keogh JB, Grieger JA, Noakes M, Clifton PM. Flow- mediated dilatation is impaired by a highsaturated fat diet but not by a high-carbohydrate diet. Arterioscler Thromb Vasc Biol 2005;25(6):1274-9.

14. Jackson KG, Armah CK, Minihane AM. Meal fatty acids and postprandial vascular reactivity. Biochem Soc Trans 2007;35(3):451-3.

15. West SG. Effect of diet on vascular reactivity: an emerging marker for vascular risk. Curr Atheroscler Rep 2001;3(6):446-55.

16. Ong PJ, Dean TS, Hayward CS, Della Monica PL, Sanders TA, Collins P. Effect of fat and carbohydrate consumption on endothelial function. Lancet 1999;354 (9196):21-34.

17. Steer P, Sarabi DM, Karlström B, et al. The effect of a mixed meal on endothelium-dependent vasodilation is dependent on fat content in healthy humans. Clin Sci (Lond) 2003;105(1):81-7.

18. Esser D, Oosterink E, op't Roodt J, et al. Vascular and inflammatory high fat meal responses in young healthy men; a discriminative role of IL- 8 observed in a randomized trial. PLoS One 2013;8(2):e53474.

19. Ahmad M, Akhter S, Masoodi SR. Wazwan the Kashmiri cuisine - a caloric bomb. Journal of Medical Sciences 2012;15(2): 174-75.

20. Harte AL, Varma MC, Tripathi G, et al. High fat intake leads to acute postprandial exposure to circulating endotoxin in type 2 diabetic subjects. Diabetes Care 2012;35(2):375-82.

21. Ghoshal S, Witta J, Zhong J, de Villiers W, Eckhardt E. Chylomicrons promote intestinal absorption of lipopoly- saccharides. J Lipid Res 2009;50(1):90-7.

22. Vogel RA. Heads and hearts: the endothelial connection. Circulation 2003;107(22):2766-8.

23. Lipovetzky N, Hod H, Roth A, Kishon Y, Sclarovsky S, Green MS. Heavy meals as a trigger for a first event of the acute coronary syndrome: a case-crossover study. Isr Med Assoc J 2004;6(12):728-31. 